\title{
O VETO PARCIAL NO SISTEMA CONSTITUCIONAL BRASILEIRO
}

\author{
André Corrêa de Sá Carneiro*
}

Resumo: Este artigo analisa a instituição do veto parcial no sistema constitucional brasileiro, suas características, seus precedentes, e os efeitos causados na atividade legiferante em decorrência de sua utilização. Expõe, ainda, que o veto tem o objetivo de gerar equilíbrio entre os Poderes, contrabalançando a competência do Legislativo por parte do Chefe do Poder Executivo. Também se aponta que a criação do veto parcial foi fundamentada pela questão dos riders ou caudas orçamentárias, que são dispositivos anexados ao projeto de lei, por meio de emendas, com o objetivo de ser sancionado pelo Presidente da República. Ao final, pondera sobre a questão do abuso do poder do veto, quando este é transformado em mecanismo que permite ao Presidente da República exercer atividade legiferante exclusiva do Poder Legislativo.

Palavras-chave: veto parcial; veto; cauda orçamentária; abuso do poder do veto; freios e contrapesos; processo legislativo; relações executivo-legislativo.

Abstract: The article analyzes the establishment of partial veto within the brazilian constitutional system, examining its characteristics, precedents and reflexes in law-making process. It exposes that the veto seeks to generate balance between legislative and executive branches. It also declares that the creation of partial veto was based on the usage of riders - amendments attached to the bill, aiming to be validated by the president. Finally, it considers the possibility of the veto be overused, what could allow the president to exert law-making, legislative branch's exclusive activity.

Keywords: partial veto; item veto; veto; rider; amendments; abuse of veto power; checks and balances; legislative process; law-making process; executive-legislative relations.

\footnotetext{
* Mestrando em Ciência Política (Iuperj-CD); Especialista em Processo Legislativo (Cefor/CD), Direito do Estado (Universidade Cândido Mendes - Ucam) e Direito Administrativo e Processo Administrativo (Universidade Cândido Mendes - Ucam); Chefe de Gabinete de Liderança Partidária e Analista Legislativo da Câmara dos Deputados; andre.carneiro@camara.gov.br.
} 


\section{Introdução}

O Direito pátrio consagra o poder de veto ${ }^{1}$ como mecanismo ínsito na técnica, teorizada por Bolingbroke (BONAVIDES, 2006), de checks and balances, ou freios e contrapesos, exsurgindo como forma de contrabalançar a competência legiferante do Congresso Nacional por parte do Chefe do Poder Executivo dentro do sistema de controle recíproco da ação dos poderes.

Com efeito, Montesquieu, em De l'Esprit dês Lois, já propalava teoria com o objetivo de gerar equilíbrio entre os Poderes, discernindo a faculdade de estatuir (faculté de statuer) da faculdade de impedir (faculte d'empêcher), antecipando, dessarte, a técnica dos freios e contrapesos (BONAVIDES, 2006). Assim, quando o Presidente da República utiliza-se do veto para refrear determinado projeto de lei, o faz no uso de sua faculdade de impedir que a proposição se transforme em lei.

Não obstante, a utilização dessa prerrogativa deve ser fundamentada. Duas são as justificativas para o veto: a inconstitucionalidade ou a inconveniência (FERREIRA FILHO, 2002). No primeiro caso, o Presidente veta o projeto por entendê-lo em desacordo com a Carta Política, utilizando-se, portanto, de um critério estritamente jurídico - é o chamado veto jurídico. No segundo, serve-se de um motivo eminentemente político, envolvendo uma análise de vantagem e desvantagem. Cabe ao Presidente avaliar se a matéria de que trata o projeto de lei é contrária ao interesse público. É o veto político.

\section{Características do Veto}

O veto, que consiste na manifestação de dissensão do Presidente da República em relação ao projeto de lei aprovado pelo Congresso Nacional, caracteriza-se, no sistema constitucional brasileiro, por ser um ato expresso, formal, motivado, total ou parcial, supressivo, superável ou relativo, irretratável, insuscetível de apreciação judicial.

Assim, o veto é ato expresso, ou seja, decorre sempre de uma manifestação explícita do Presidente da República, uma vez que, transcorrido o prazo prescrito para o veto sem a sua manifestação, ocorre a sanção tácita $\left(\mathrm{CF}\right.$, art. $\left.66, \S 3^{\circ}\right)$.

É ato formal, visto que deverá ser exarado por escrito, com a necessária fundamentação dos motivos do veto, para encaminhamento, em quarenta e oito horas, ao Presidente do Senado Federal.

$\mathrm{O}$ veto deve ser sempre motivado para que se saiba das razões que levaram à discordância, se relativas à inconstitucionalidade ou à falta de interesse público, ou se por ambos os motivos. Essa

\footnotetext{
${ }^{1}$ Conforme relata Alexandre de Morais, a natureza jurídica do veto não encontra unanimidade na doutrina constitucional, "existindo inúmeros juristas defensores da tese de tratar-se de direito, outros os entendem com um poder; havendo ainda tese intermediária que consagra o veto como um poder-dever do Presidente da República" (MORAIS, 2006, p. 594, grifo nosso).
} 
exigência se faz necessária para que o Poder Legislativo possa analisar as razões que conduziram o Chefe do Poder Executivo ao veto.

O Presidente da República tem a prerrogativa de vetar o projeto de lei aprovado pelo Congresso Nacional total ou parcialmente. Será total quando incidir sobre todo o projeto de lei e parcial quando recair sobre apenas alguns dos dispositivos da proposição.

O veto, no Direito brasileiro, somente poderá determinar a erradicação de dispositivos constantes de projeto de lei, não sendo possível a adição ou modificação de algo no texto da proposição, sendo, portanto, somente supressivo.

O veto é superável, relativo ou suspensivo, uma vez que não apresenta caráter absoluto, ou seja, não encerra, de forma definitiva, o processo legislativo em relação às disposições vetadas, dado que poderão ser restabelecidas pela maioria absoluta dos Deputados e Senadores, em escrutínio secreto, em sessão conjunta do Congresso Nacional (CF, art. 66, § $4^{\circ}$ ).

Uma vez manifestada pelo Presidente da República a discordância em relação ao projeto de lei ou a alguns de seus dispositivos e comunicada as razões do veto ao Presidente do Senado Federal, não pode o Chefe do Executivo arrepender-se, uma vez que o veto é irretratável. Dessa forma, não se admite a desistência do veto para o objetivo de considerar-se o projeto de lei tacitamente aprovado ${ }^{2}$.

Por fim, o veto é insuscetível de apreciação judicial, dado que, por ser ato político do Presidente da República, "é insuscetível de ser enquadrado no conceito de ato do Poder Público, para efeito de controle judicial" (PAULO e ALEXANDRINO, 2003, p. 81). Assim, o controle judicial das razões do veto não é aceito em virtude do postulado da separação dos Poderes, cabendo, somente ao Congresso Nacional, analisar e, eventualmente, superar, os motivos do veto, mormente no que tange a alegada inconstitucionalidade.

\section{O veto total no Brasil}

Michel Temer (1978), ao relatar a evolução histórica do veto no Brasil, informa que a Constituição Imperial Brasileira de 1824 já adotava o veto total, sem a possibilidade de sua rejeição pela Assembléia Geral, de acordo com a leitura dos seus artigos 62 a 70.

$\mathrm{O}$ art. 15 do Ato adicional, de 12 de agosto de 1834, entretanto, já previa o veto total ou parcial para os projetos de leis elaborados pelas Assembléias das Províncias. Um ponto importante a ser destacado é que, mesmo rejeitado o veto pela Assembléia provincial, o Presidente da Província poderia negar-lhe sanção, recomendando-lhe alterações na forma de supressão de artigos (veto parcial) ou negando-lhe por inteiro (veto total). Ainda assim, a Assembléia Geral continuava a ter a

\footnotetext{
${ }^{2}$ Veja, nesse sentido, decisão do Supremo Tribunal Federal (RDA 70/308 e ss.)
} 
regra antiga que lhe vedava reapreciar o veto.

A Constituição de 1891, por sua vez, embora só preconizasse o veto total, já permitia a rejeição do veto por dois terços dos Deputados e Senadores (art. 37, § $3^{\circ}$ ). Esse quórum qualificado de dois terços subsistiu até a Constituição de 1967 e alterações promovidas pela Emenda $n^{\circ} 1$, de 1969.

O veto parcial no direito brasileiro só foi introduzido em âmbito federal na reforma constitucional de 1926.

\section{A problemática dos riders ou das caudas}

Conforme salienta Mário Cassanta (apud SILVA, 2006), o poder de veto pressupõe um sistema de governo em haja divisão de poderes. Nesses Estados é comum a questão dos riders, dispositivos anexados ao projeto de lei, principalmente em relação aos projetos de leis anuais, chamados, nesse caso, de caudas orçamentárias.

O rider, também conhecido como pingente ou cauda, refere-se à inclusão de disposições, por meio de emenda, a um projeto de lei com o objetivo de ser sancionado pelo Presidente da República. Consoante Manoel Gonçalves Ferreira Filho, o rider

decorre da malícia parlamentar que se prevalece da importância de um projeto para com ele fazer passar uma norma qualquer que, isoladamente apresentada como projeto de lei, não chegaria a vingar porque sabidamente não seria sancionada pelo chefe do Governo. O projeto preferido para essas adjunções é o do orçamento, pela evidente importância que tem para todo o Governo. Por intermédio de emenda, o parlamentar inclui num projeto importante um pingente, que em geral nada tem a ver com a matéria daquele, a fim de colocar o chefe do Governo no dilema de sancionar o projeto com o "rider", apesar da inconveniência ou necessidade deste, para fulminar a cauda parasitária (FERREIRA FILHO, 1971, p. 34-35, grifo do autor).

Foi com o objetivo de eliminar os riders que se imaginou a criação do veto parcial, permitindo ao Chefe do Poder Executivo expurgar as disposições estranhas inseridas no projeto de lei.

\section{0 veto parcial: precedentes estrangeiros}

Nos Estados Unidos da América, foi criado o chamado item veto, com a finalidade de derriscar os riders dos projetos de lei. A Constituição da Pensilvânia foi a primeira a estabelecer, em 1873, o veto parcial para leis orçamentárias, exemplo seguido por várias outras constituições estaduais que deram ao veto parcial esse mesmo alcance.

Corwin (apud FERREIRA FILHO, 1971), em sua obra The President: Office and Powers, expende que, após 1873, diversas emendas à Constituição federal foram apresentadas com o fito de conceder ao Presidente o item veto ou selective veto. Ainda, assinala que Roosevelt, em 1938, e 
Eisenhower, em 1957, reivindicaram, sem sucesso, sua instituição, tendo em vista o aumento da utilização de caudas orçamentárias.

Também a Argentina apresenta, nas Constituições estaduais de Entre Rios, Catamarca e San Luis, exemplos de adoção do veto parcial em amplitude e alcance bem próximos do existente no Direito brasileiro.

Não obstante, a Constituição Argentina (art. 72) prevê que o veto parcial importa em nova apreciação do projeto inteiro, suspendendo, desse modo, até que o Congresso finalize essa deliberação, a entrada em vigor da parte não vetada e, portanto, sancionada do projeto (NOVARO e HRONCICH apud FERREIRA FILHO, 1971).

Destaca Haroldo Valadão que a Constituição Mexicana dispõe sobre o veto parcial de forma idêntica à Constituição Argentina, conforme informa F. Tena Ramírez:

Según dicho precepto, el proyeto de ley o decreto desechado em todo o em parte pro el ejecutivo, será devuelto, con sus observaciones, a la Cámara de su origen; ceberá ser discutido de nuevo por ésta, y si fuese confirmado por las dos terceras partes del número total de votos, pasará otra vez a la Cámara revisora; si por ésta fuese sancionado por la misma mayoría, el proyeto será lei o decreto y volverá al ejecutivo para su promulgación (VALLADÃO, 1958, p. 18)

\section{A adoção do veto parcial no sistema constitucional brasileiro}

Manoel Gonçalves Ferreira Filho (1971) afirma que o instituto do veto parcial foi adotado pela primeira vez no Brasil no âmbito das Constituições estaduais, em que pese sua previsão contida no art. 15 do Ato adicional, de 12 de agosto de 1834 (TEMER, 1978). As Constituições da Bahia, do Maranhão e de Minas Gerais (FERREIRA FILHO, 1971), bem como a do Pará e a do Ceará (NUNES e CASSANTA apud VALLADÃO, 1958) já aceitavam o veto parcial do Chefe do Executivo antes mesmo da revisão constitucional de 1926.

A instituição do veto parcial na Constituição Federal foi motivada pela necessidade que teve o Presidente Epitácio Pessoa de vetar totalmente a Lei do Orçamento da Despesa para 1922 para não sancionar as caudas orçamentárias, então existentes, em seu texto (VALLADÃO, 1958).

Mário Cassanta expende que o então governador de Minas Gerais, Artur Bernardes, logrou êxito em incluir, em 1920, na Constituição mineira, o veto parcial para qualquer projeto de lei, nestes termos:

O veto só poderá ser parcial, quando a parte vetada e a sancionada não forem mutuamente dependentes e conexas, de maneira que, com a sua supressão, a parte sancionada continue a ser um ato inteligível e completo, correspondendo, em conjunto, à intenção e propósitos do Congresso (CASSANTA apud SILVA, 2006, p. 222).

Cumpre observar que essa disposição, que Ferreira Filho relata ser a primeira a prever o 
veto parcial para qualquer projeto de lei no Direito brasileiro ${ }^{3}$, apresenta justa e prudente limitação ao poder de veto.

Artur Bernardes, ao assumir a Presidência da República, imprimiu influência decisiva para que, na revisão constitucional de 1926, fosse incluído dispositivo que criasse, em âmbito federal, o veto parcial. O art. 37, § $1^{\circ}$, da Constituição Federal de 1891, com a emenda de 1926, assim ficou:

Quando o Presidente da República julgar um projeto de lei, no todo ou em parte, inconstitucional ou contrário aos interesses nacionais, o vetará, total ou parcialmente, dentro de 10 dias úteis a contar daquele em que o recebeu, devolvendo, nesse prazo e com os motivos do veto o projeto, ou a parte vetada, à Câmara onde ele se houver iniciado.

As Constituições Federais seguintes (1934, art. 45; 1937, art. 66, § 1º 1946, art. 70, § 1; 1967, art. 62, § $1^{\circ}$; Emenda $n^{\circ} 1$ de 1969, art. 59, § $1^{\circ}$; 1988, art. 66, $\S 2^{\circ}$ ) mantiveram o veto parcial, dispondo de forma bem semelhante ao estatuído na Emenda de 1926. Somente a Emenda ${ }^{\circ}$ 17, de 1965, à Constituição de 1946; a Constituição de 1967, com texto anterior à Emenda $n^{\circ}$ 1, de 1969; e a Constituição de 1988 adicionaram limitação quanto ao seu alcance. As duas primeiras restringiram o veto parcial nos seguintes termos: "O veto parcial deve abranger o texto de artigo, parágrafo, inciso, item, número ou alínea" enquanto a Constituição atual dispôs da seguinte forma: "O veto parcial somente abrangerá texto integral de artigo, de parágrafo, de inciso ou de alínea".

\section{O veto parcial no Direito Constitucional brasileiro}

Conforme já analisado, o veto parcial, no Direito Constitucional brasileiro, pode ser utilizado em qualquer projeto de lei, tratando de matéria orçamentária ou não. De acordo com o $\S 1^{\circ}$ do art. 66 da Carta Política vigente, tanto o veto total quanto o parcial podem ser apostos, no prazo de quinze dias úteis, caso o Presidente da República considere o projeto inconstitucional ou contrário ao interesse público. Cumpre salientar que a Constituição atual só permite o veto parcial incidente sobre texto integral de artigo, de parágrafo, de inciso ou de alínea $\left(\mathrm{CF}\right.$, art. $\left.66, \S 2^{\circ}\right)$.

Cabe notar, ainda, que a doutrina dominante entende que o Chefe do Executivo pode vetar, total ou parcialmente, inclusive, projeto de lei de sua iniciativa que tenha sido aprovado pelo Poder Legislativo sem nenhuma alteração (PAULO e ALEXANDRINO, 2003). Essa mudança de interesse em relação a determinado projeto pode ocorrer, por exemplo, devido à demora em sua apreciação pelo Poder Legislativo e pelo fato de essa matéria não mais se adequar ao programa de governo adotado pelo Executivo (SILVA, 2006).

O veto será apreciado em sessão conjunta do Congresso Nacional, dentro de trinta dias a

\footnotetext{
${ }^{3}$ Acrescenta que as demais Constituições estaduais permitiam o veto parcial apenas para leis orçamentárias (FERREIRA FILHO, 1971).
} 
contar do recebimento pelo Presidente do Senado Federal, só podendo ser rejeitado pelo voto da maioria absoluta dos Deputados e Senadores - separadamente -, em escrutínio secreto (CF, art. 66, $\S 4^{\circ}$ ). Interessante observar que atualmente vota-se contra ou a favor do veto, enquanto que, nas Constituições passadas, votava-se contra ou a favor do projeto.

Dessa forma, o projeto converter-se-á em lei se a maioria dos Deputados e Senadores rejeitarem o veto, dispensando-se, nesse caso, a sanção. Não se atingindo esse quórum qualificado nas duas Casas estará ele mantido e o projeto, ou parte do projeto que foi vetado, será arquivado. Importa notar que é factível, no Direito Constitucional brasileiro, a rejeição parcial do veto total, ou, até mesmo, a rejeição parcial do veto parcial.

Em sendo o veto rejeitado, a agora lei - uma vez que a rejeição do veto tem o condão de transformar o projeto em lei -, será encaminhada ao Presidente da República para promulgação e publicação.

Diferindo completamente do Direito argentino, o veto parcial não suspende a entrada em vigor na parte não vetada. Somente a parte vetada é sujeita a reapreciação do Congresso Nacional, enquanto a restante é sancionada, promulgada, publicada, passando, então, a viger.

Daí decorre que, uma vez derrubado o veto parcial, segue o texto dessa parte para promulgação, publicação e entrada em vigor, o qual ocorrerá em data posterior ao do texto não vetado, acarretando, portanto, duas datas de vigência para a mesma lei: uma da parte sancionada e outra da parte cujo veto foi rejeitado. Nesse sentido, Ferreira Filho assim se manifesta sobre o tema:

A imediata entrada em vigor da parte não vetada, que é possível no Direito brasileiro, apresenta vantagens, mas também desvantagens graves. Sem dúvida, é vantajoso que as disposições estabelecidas pelo Congresso e aprovadas pelo Presidente possam desde logo ser aplicadas. Todavia, se superado o veto, ocorre o inconveniente tantas vezes sentido entre nós de uma mesma lei ter vigorado com um texto (o da publicação sem a parte vetada, até a publicação do texto com a parte que fora vetada incluída) e passar a vigorar com outro texto. Esse inconveniente tem até provocado a prática esdrúxula de a parte vetada ser publicada com outro número, como se fosse outra lei. Dessa situação (em vigor a parte não vetada, pendente a parte vetada) resulta sempre incerteza sobre o alcance e o verdadeiro sentido da lei, o que redunda necessariamente em insegurança jurídica (FERREIRA FILHO, 2002 , p. 224, grifos nossos).

\section{O abuso do poder de veto}

O veto foi engendrado pela doutrina clássica consoante a lição de Monstesquieu, isto é, como faculdade de impedir (faculte d'empêcher). Portanto, tem por objetivo permitir que o Chefe do Executivo possa impedir, ou pelo menos dificultar, que dispositivos inconstitucionais ou 
inconvenientes para o bem comum se transformem em leis. É, pois, o veto instrumento de controle da ação parlamentar e dessa forma foi acolhido pelo Direito Constitucional brasileiro.

Entrementes, a prática tem demonstrado utilização diversa do poder de vetar parcialmente projetos de lei, transformando-o em mecanismo que permite ao Presidente da República legislar, o que se configura em absurdo, no entendimento de notáveis doutrinadores ${ }^{4}$, conforme lição de Manoel Gonçalves Ferreira Filho: “A prática constitucional brasileira revela que no período posterior a 1926 os Presidentes da República brasileira souberam transformar o veto parcial em instrumento de legislação, mudaram o seu caráter de 'faculté d'empêcher' para 'faculté de statuer'” (FERREIRA FILHO, 1971, p. 35).

Com efeito, a situação era mais gravosa na vigência das Constituições 1891 (a partir de sua alteração em 1926), 1934, 1946 (no período anterior à Emenda n 17, de 1965), 1967 (com texto anterior à Emenda $n^{\circ}$ 1, de 1969), uma vez que não havia limitação que impedisse que o veto pudesse ser aposto a palavras isoladas, frases e orações de dispositivo, modificando, dessa feita, o conteúdo da norma.

Outro agravante era que, até a Constituição de 1967 - com as alterações promovidas pela Emenda $\mathrm{n}^{\circ}$ 1, de 1969 -, para que se derrubasse o veto, era necessário alcançar o quórum mínimo de dois terços dos Deputados e Senadores. Assim, se o Presidente obtivesse o apoio de um terço mais um dos parlamentares, conseguiria impor suas mudanças alcançadas por meio do veto parcial. Contudo, esse abuso foi aceito pela jurisprudência, inclusive pela Corte Suprema. Ressalta ainda Manoel Gonçalves Ferreira Filho que

a gravidade dessa prática era ainda realçada pelo fato de que dava ensejo a uma verdadeira legislação minoritária por parte do Executivo. De fato, sendo necessária maioria qualificada para a rejeição do veto, o desnaturamento da lei era mantido, desde que uma minoria do Congresso, superior, todavia, a um terço, apoiasse o Presidente. $\mathrm{O}$ veto parcial servia, destarte, para fraudar a vontade do Congresso, manifestada na aprovação do projeto em termos muito diferentes daqueles em que este se tornava lei (FERREIRA FILHO, 2002, p. 223, grifos nossos).

Exemplo relevante desse tipo de arbitrariedade ocorreu por ocasião da elaboração da antiga Lei Orgânica dos Partidos Políticos, Lei $n^{\circ}$ 4.740/65. O Congresso Nacional aprovou esse projeto de lei objetivando introduzir profunda reorganização. Entretanto, constava nessa proposição disposição que beneficiaria os partidos existentes à época, permitindo conservar a existência legal desde que preenchessem "ao menos uma das seguintes condições" que enumerava (art. 47) (FERREIRA FILHO, 1971).

O Presidente da República, almejando dificultar o que o Congresso intencionava facilitar, vetou a expressão "ao menos uma das", transformando, portanto, em cumulativas as exigências que

${ }^{4}$ Acordam nesse sentido Mário Cassanta, Themístocles Cavalcanti, Manoel Gonçalves Ferreira Filho, José Afonso da Silva, Alexandre de Moraes, entre outros. 
o Poder Legislativo queria fossem alternativas. Dessa forma, o art. 47 ficou, assim, dispondo: “Ainda se cancelará o registro do partido que não satisfazer ... seguintes condições:”. Mesmo com o agravante de o dispositivo ter ficado com essa redação claudicante, o veto não obteve o quórum necessário para ser derrubado, prevalecendo, por conseguinte, esse texto.

Outro exemplo clássico, de contornos mais graves, ocorreu no Estado de São Paulo, quando projeto de lei financeira, contendo aumento na alíquota do imposto de vendas e consignações (então existente), foi aprovado no Congresso com cláusula de vigência prevista para noventa dias após a publicação, tendo por finalidade dar tempo aos contribuintes para que se preparassem para cumprila adequadamente. Porém, o Governador do Estado vetou, desse artigo, a expressão "noventa dias". Dessa feita, a lei foi promulgada e publicada com essa truncada redação: "Esta lei entrará em vigor ... a sua publicação", impondo seus efeitos de imediato para toda a população (SILVA, 2006). Esse veto posteriormente foi mantido e considerado válido pelos Tribunais ${ }^{5}$.

Com o objetivo de evitar o mau uso do veto parcial, a Constituição de 1988 dispôs que "o veto parcial somente abrangerá texto integral de artigo, de parágrafo, de inciso ou de alínea”. De igual sorte, foi alterado o quórum necessário para se derrubar o veto de dois terços para maioria absoluta dos Deputados e Senadores. Cumpre lembrar, conforme já exposto, que a Emenda $n^{\circ} 17$, de 1965, à Constituição de 1946, e a Constituição de 1967, com texto anterior à Emenda n ${ }^{\circ}$, de 1969, também limitaram o veto parcial a texto integral de dispositivo.

Apesar da introdução dessas alterações, é comum o Chefe do Poder Executivo utilizar-se do veto parcial de forma a modificar o conteúdo da norma, contrariando a própria finalidade do veto parcial e dando à lei contorno e substância que o legislador não quis. Conforme salienta Michel Temer, "o todo lógico da lei pode desfigurar-se também pelo veto, por inteiro, do artigo, do inciso, do item ou da alínea. E até com maiores possibilidades". E acrescenta que "se isto ocorrer - tanto em razão do veto de palavra ou de artigo - o que se verifica é usurpação de competência pelo Executivo, circunstância vedada pelo art. $2^{\circ}$ da CF" (TEMER, 2006, p. 236).

Destarte, o veto parcial, imaginado e proposto com o fito de eliminar abusos por parte dos parlamentares, veio a se tornar, no Brasil, mecanismo a permitir abusos por parte do Presidente da República. Deve ele, portanto, limitar-se a finalidade pela qual foi criado, o de eliminar dos projetos de lei aprovados pelo Legislativo as caudas, os pingentes, os riders.

Por fim, pode-se entender o veto como um convite do Poder Executivo ao Legislativo no sentido de que este aperfeiçoe a elaboração de normas legais, aprovando-as sem o estigma da inconstitucionalidade ou da matéria inconveniente. O que não pode ocorrer, entretanto, é a substituição do Legislativo pelo Executivo na atividade legiferante, função precípua daquele Poder.

\footnotetext{
${ }^{5}$ Vide RDA, vol. 87/60.
} 


\section{Referências}

BONAVIDES, Paulo. Ciência Política. 12. ed. São Paulo: Malheiros, 2006.

FAGUNDES, Miguel Seabra. Dos efeitos do veto parcial até a sua apreciação pelo Congresso. Arquivos do Ministério da Justiça e Negócios Interiores, vol. 20, n. 83, p. 12 a 14, set. 1962. FERREIRA FILHO, Manoel Gonçalves. O veto parcial no Direito Brasileiro. Revista de Direito Público, v.4, n.17, p.33-37, jul./set. 1971.

. Do Processo Legislativo. 5. ed. São Paulo: Saraiva, 2002.

HORTA, Raul Machado. Direito Constitucional. 3. ed. Belo Horizonte: Del Rey, 2002.

MASSENA, Nestor. Veto Parcial. Revista de Direito Administrativo, vol. 26, p. 441 a 443, out/dez 1951.

MORAES, Alexandre de. Direito Constitucional. 19. ed. São Paulo: Atlas, 2006.

MOTTA, Sylvio e DOUGLAS, William. Direito Constitucional: teoria, jurisprudência e 1000 questões. 16 ${ }^{\mathrm{a}}$ ed. Rio de Janeiro: Elsevier, 2005.

PAULO, Vicente e ALEXANDRINO, Marcelo. Processo Legislativo. Rio de Janeiro: Impetus, 2003.

PONTES, Elio Monnerat Solon de. Da Publicação de lei, objeto de veto parcial, antes da apreciação deste pelo poder legislativo. Rio de Janeiro: Imprensa Nacional, 1954.

SILVA, José Afonso da. Curso de Direito Constitucional Positivo. $27^{\mathrm{a}}$ ed. rev. e atual. São Paulo: Malheiros, 2006.

. Processo Constitucional de Formação das Leis. $2^{\text {a }}$ ed. São Paulo: Malheiros, 2006.

TEMER, Michel. O veto parcial no sistema constitucional brasileiro. Revista da Procuradoria Geral do Estado de São Paulo, n. 12, 229-238, jun. 1978.

. Elementos de Direito Constitucional. 21 a ed. rev. e atual. São Paulo: Malheiros, 2006.

VALLADÃO, Haroldo. Natureza e efeitos do veto parcial. Revista forense, v.55, n.178, p.18-27, jul./ago. 1958. 